'Department of Cardiology, University Hospital, Basel, Switzerland.

\section{Key Words:}

Diabetes mellitus . Coronary artery disease. Silent ischemia - Myocardial perfusion SPECT · Prognosis

Herz 2006;31:240-5

DOI $10.1007 /$

s00059-006-2790-1

\section{Schlüsselwörter:}

Diabetes mellitus Typ $2 \cdot$ Koronare Herzkrankheit. Stumme Ischämie · Myokardiale Perfusionsszintigraphie $\cdot$ Prognose

\title{
Prognostic Significance of Silent Coro- nary Artery Disease in Type 2 Diabetes
}

\author{
Michael J. Zellweger ${ }^{1}$
}

\begin{abstract}
The prevalence of obesity and diabetes is increasing rapidly. Coronary artery disease (CAD) represents the leading cause of death in diabetic patients. Diabetic patients are at a two- to fourfold risk of cardiovascular mortality compared with their nondiabetic counterparts. Silent myocardial ischemia more often occurs in diabetics than in nondiabetics. In general, the prevalence of silent $C A D$ varies depending on the test used for patient screening and on the patient population screened. The prevalence of silent CAD is $6-23 \%$ in low-risk diabetic patients. In high-risk diabetic patients the prevalence may be as high as $60 \%$. Over the last
\end{abstract}

years it has been well recognized that silent CAD is not different from symptomatic CAD with respect to prognosis and adverse events. Particular diabetic patients therefore might benefit from routine CAD screening. CAD could be diagnosed at an earlier stage of disease and be treated accordingly. Myocardial perfusion SPECT, stress echocardiography and possibly computed tomography are emerging as effective screening tools beyond risk stratification by risk factor scoring systems alone. There are few studies suggesting that early intervention by medical or also revascularization strategies could lead to a better outcome in diabetic patients with evidence of silent CAD.

\section{Prognostische Bedeutung der stummen KHK beim Typ-2-Diabetes}

\section{Zusammenfassung}

Adipositas und Diabetes nehmen in ihrer Häufigkeit rasch zu. Eng damit verbunden ist eine sich entwickelnde „Epidemie“ der koronaren Herzkrankheit (KHK). Diabetiker haben eine zwei- bis vierfach höhere kardiovaskuläre Mortalität als Nichtdiabetiker. Zudem verläuft die KHK bei Diabetikern nicht selten stumm. Das Symptom der Angina pectoris stellt lediglich die Spitze des Eisberges der ischämischen Kaskade dar (Abbildung 1). Die Prävalenz der stummen KHK hängt vom verwendeten Screeningtest und von der untersuchten Patientenpopulation ab. Bei Diabetikern mit niedrigem Risiko liegt die Prävalenz der stummen KHK bei 6-23\%. Bei diabetischen Patienten mit höherem Risiko (Patienten mit Endorganschäden wie peripherer arterieller Verschlusskrankheit, Mikroalbuminurie, Retinopathie, autonomer kardialer Neuropathie) ist sie deutlich höher. Je nach Studie leiden bis 60\% dieser Patienten an einer stummen KHK. Mögliche Ursachen für das Vorliegen einer stummen KHK sind in Tabelle 1 aufgeführt. Für die Untersuchung von Patienten mit stummer Ischämie stehen uns heute mehrere effektive bildgebende Verfahren zur Verfügung (myokardiale Perfusions-szintigraphie [MPS] in Ruhe und bei Belastung, Stressechokardiographie, Stressmagnetresonanztomo- graphie und möglicherweise auch die hochauflösende Computertomographie zur nichtinvasiven CT-Angiographie). Für die MPS gibt es gegenwärtig noch die besten Daten bezüglich Prävalenz und Prognose der stummen KHK. Diabetische Patienten mit einem normalen MPS haben eine verhältnismäßig gute Prognose, wenn auch die jährliche kardiovaskuläre Ereignisrate nicht < $1 \%$ liegt, wie dies für Nichtdiabetiker mehrfach an großen Patientengruppen gezeigt werden konnte (Abbildungen 2 und 3). Die Hinweise mehren sich, dass nicht so sehr die Symptomatik der Diabetiker, sondern vielmehr die objektive Evidenz einer KHK für die Prognose entscheidend ist. Dementsprechend sollten alle Diabetiker mit hohem Risiko, aber auch atypischen Beschwerden hinsichtlich einer KHK untersucht werden. Liegen Hinweise für eine stumme KHK vor, legen die ersten Studienergebnisse nahe, dass auch die Therapie von asymptomatischen Diabetikern deren Prognose verbessern kann. Zudem ist im Alltag zu beachten, dass auch ein normaler Ischämiesuchtest lediglich eine Momentaufnahme darstellt und je nach Patientenrisiko nach einem gewissen Zeitintervall wiederholt werden sollte („Garantiedauer“ eines normalen Tests). 


\section{Introduction}

The prevalence of obesity and diabetes is increasing rapidly which is due to human behavior and lifestyle changes. Sedentary lifestyle, rich nutrition and obesity are precursors of diabetic development. Worldwide, there will be an increase of diabetes incidence from 151 million patients in the year 2000 to 221 million patients in the year 2010 which is consistent with an increase of $46 \%$ [1]. Furthermore, there are several studies suggesting that diabetic patients without prior coronary artery disease (CAD) have as high a risk of myocardial infarction as nondiabetic patients with prior myocardial infarction [2]. An autopsy study demonstrated that among diabetic decedents without clinical CAD, almost $75 \%$ of patients had high-grade coronary atherosclerosis and $>$ $50 \%$ had multivessel disease. In the absence of diabetes, women had less coronary atherosclerosis than did men, but this female advantage was lost with diabetes [3]. In addition, CAD represents the leading cause of death in patients with diabetes [4]. Atherosclerosis accounts for $65-80 \%$ of all deaths among diabetic patients, compared with one third of all deaths in the general population [5]. The cardiovascular mortality rate is more than twice as high in diabetic men and more than fourfold greater in diabetic women, compared with their nondiabetic counterparts [6]. These facts add to the prospect that an "epidemic" of CAD will emerge over the coming decades.

Since diabetics often present with silent CAD, they lack an important clinical "warning symptom" of their CAD.

The aim of this review therefore is fourfold: (1) to discuss the definition and the potential mechanisms of silent CAD in diabetic patients; (2) to summarize published data dealing with the prevalence of silent CAD; (3) to look at the prognostic significance of silent CAD in diabetes; (4) to elucidate first therapeutic approaches in silent CAD.

\section{Definition and Potential Mechanisms of Silent CAD}

Silent CAD is a term generally used to describe CAD or myocardial ischemia in the absence of chest pain or angina but in the presence of objective evidence of myocardial ischemia or CAD. Chest pain and angina represent only the "tip of the iceberg" in the ischemic cascade (Figure 1). There is a close interaction of coronary stenosis, decreased myocardial perfusion, and impaired myocardial function before patients notice chest pain. Nowadays, cardiac examination techniques provide possibilities to monitor the ischemic cascade at its several steps. The gold standard to visualize coronary artery stenosis still is coronary angiography. Even though, computed tomography $(\mathrm{CT})$ is a rapidly developing and emerging tool for the assessment of ischemic heart disease, including visualization of the coronary arteries.
Noninvasive coronary imaging still poses the greatest challenge to any diagnostic technique. This is due to the fact that the coronary arteries are small, tortuous, and course in multiple planes around the heart, whereas cardiac contraction and respiration cause motion artifacts. There are several tools to monitor myocardial perfusion. The most robust and standardized method is still myocardial perfusion SPECT (MPS) and positron emission tomography (PET) although magnetic resonance (CMR) has huge potential to emerge as an effective imaging technique in the assessment of CAD. For stress echocardiography similar sensitivities and specificities may be expected as for MPS, if there is a good acoustic window; however, "diabetic cardiomyopathy" may limit this test to identify CAD in diabetics. Currently, outcome data in diabetic patients following stress echocardiography is still too limited to define its role as a prognostic tool in these patients.

The advantage of cardiac imaging techniques when compared to stress testing without imaging is the possibility to gather a lot of additional information, e.g., the extent and amount of ischemia and left ventricular ejection fraction.

The reasons for silent CAD in diabetes are plenty [7-10]. Table 1 summarizes the mostly discussed mechanisms.

\section{Prevalence of Silent CAD}

In general, the prevalence of silent myocardial ischemia varies depending on the patient population screened and the test used for patient evaluation. In patients without known prior $\mathrm{CAD}$, the prevalence of silent CAD is $2.5-11 \%$ in nondiabetic patients as compared to $6.4-23 \%$ in low-risk diabetic patients [11-15].

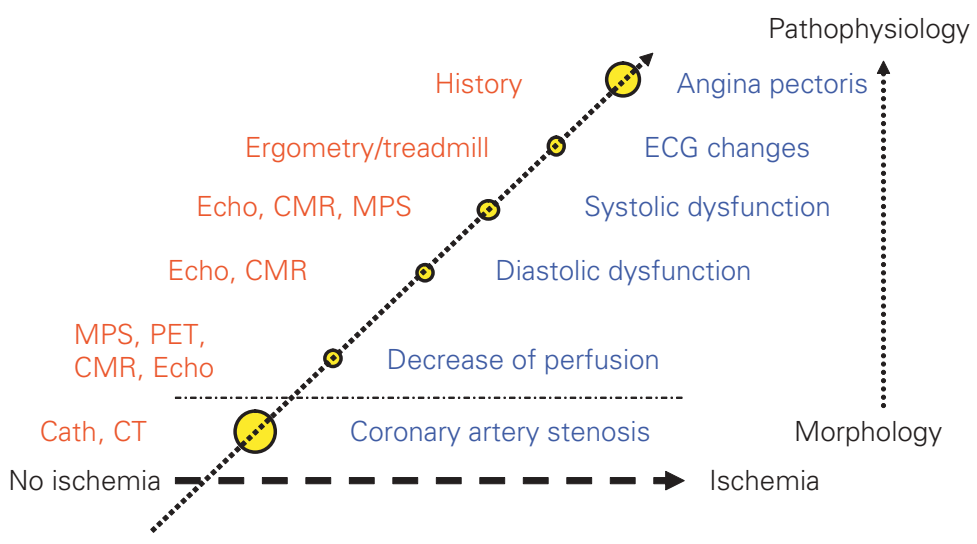

Figure 1. Ischemic cascade. Cath: coronary angiography; CMR: cardiac magnetic resonance; CT: computed tomography; Echo: echocardiography; MPS: myocardial perfusion SPECT; PET: positron emission tomography.

Abbildung 1. Ischämische Kaskade. Cath: Herzkatheter; CMR: Magnetresonanztomographie des Herzens; CT: Computertomographie; Echo: Echokardiographie; MPS: myokardiale Perfusionsszintigraphie; PET: Positronenemissionstomographie. 
Table 1. Reasons for silent coronary artery disease/ischemia.

Table 1. Gründe für die stumme koronare Herzkrankheit/ Ischämie.

- Lesser severity and duration of ischemia

- Prior Q-wave myocardial infarction

- Diabetes mellitus

- Autonomic cardiac dysfunction

- Coronary collateral flow

- Psychological characteristics, such as decreased awareness of somatic pain and other body sensations

- Lower depression scores

- Enhanced secretion of endogenous opiates may minimize perception of pain

${ }^{\text {a }}$ collateral flow may be so marked, that myocardial perfusion becomes normal

To date, there is only one study that has prospectively evaluated the prevalence of silent CAD in diabetic patients. Wackers et al. conducted the Detection of silent myocardial Ischemia in Asymptomatic Diabetic subjects (DIAD) study [16]. 522 patients were screened by MPS. Of these, $22 \%$ had an abnormal stress test result. Cardiac autonomic neuropathy turned out to be the only independent predictor of abnormal MPS - none of the well-known CAD risk factors.

There are groups of diabetic patients that are at particularly high risk of silent CAD. These groups are in part defined by other diabetic end-organ damages: peripheral arterial disease, cerebrovascular disease, nephropathy (microalbuminuria), retinopathy, and autonomic cardiac neuropathy.

Nesto et al. assessed the prevalence of silent CAD in a small population of patients with known peripheral vascular disease $(n=30)$ [17]. 17 patients $(57 \%)$ had thallium abnormalities, with reversible thallium defects compatible with ischemia in 14 patients $(47 \%)$ and evidence of prior, clinically silent myocardial infarction in eleven patients $(37 \%)$. With respect to nephropathy, Rutter et al. described a significant difference in positive exercise treadmill tests of diabetic patients with microalbuminuria $(65 \%)$ versus patients without microalbuminuria $(40 \% ; \mathrm{p}=0.013)$ [18]. A pooled analysis revealed that the prevalence of silent CAD was $28 \%$ and $10 \%$, in patients with and without autonomic cardiac neuropathy, respectively [19]. However, it is difficult to find data regarding the relation of retinopathy, cerebrovascular disease and silent CAD.

Prognosis of Silent CAD in Diabetic Patients The relatively high prevalence of silent CAD in particular diabetic patient populations stresses the fact that prognostic considerations of this problem are crucial.
There is limited data about the prognosis of diabetic patients with silent CAD. In general, it has been shown that the cardiovascular mortality rate is more than doubled in diabetic men and raised more than fourfold in diabetic women, when compared with their nondiabetic counterparts $[6,20]$. In addition, diabetic patients are less likely to survive a first myocardial infarction than nondiabetic patients [21].

In a large patient population $(n=1,437)$, Weiner et al. demonstrated that when myocardial ischemia (whether silent or symptomatic) was present during exercise testing, the long-term survival among diabetics was worse than that of nondiabetics [22]. By contrast, when ischemia was absent, there was no higher mortality risk for diabetic patients. Importantly, survival rates among patients with silent ischemia were similar to those of symptomatic patients regardless of diabetic status. These findings are consistent with another survival analysis by Pancholy et al. [23] that demonstrated no significant difference in the event-free survival in 521 patients with symptomatic or silent ischemia over the time period of 2 years. The extent of perfusion abnormality and history of diabetes were the most important predictors of events.

Rajagopalan et al. examined angiographic findings and mortality rates in 826 asymptomatic diabetic patients with respect to MPS findings [24, 25]. The mortality rate in high-risk patients was $5.9 \%$, in intermediate-risk patients $5.0 \%$, and in low-risk patients $3.6 \%$ ( $\mathrm{p}<0.001$ for differences between groups). Post hoc analyses were performed to determine if a truly low-risk (annual mortality $<1 \%$ ) subset of patients could be identified. Annual mortality in patients without ECG Q-waves or peripheral arterial disease and with a completely normal SPECT imaging scan ( $\mathrm{n}=$ 443 ) was lower but was still $2.9 \%$. The annual mortality rate was higher in patients with preoperative versus other indication for MPS evaluation (5.9\% vs. $2.7 \% ; \mathrm{p}<0.001)$. The annual mortality rate for patients without preoperative indication whose scan was normal $(\mathrm{n}=298)$ amounted to $1.9 \%$. For patients without preoperative indication, Q-waves, or peripheral arterial disease, the annual mortality rate was $1.6 \%$ for those with a normal scan $(\mathrm{n}=237)$ and $3.4 \%$ for those with a high-risk scan $(\mathrm{n}=79)$. Importantly, although a normal MPS study is generally associated with a low risk $(<1 \%$ annual risk of cardiac death or myocardial infarction), the challenge in a diabetic population is to define the elusive "low-risk" patient. To date, reports have consistently shown that normal MPS in diabetic populations is not associated with this low level of risk and, in direct comparisons, patients with diabetes are at significantly greater risk than nondiabetics with normal MPS [24, 26-29]. Similarly, in the setting of an abnormal MPS, the risk conferred by any given extent and severity of perfusion 
abnormality is greater in patients with diabetes than in nondiabetics.

We assessed the incidence of MPS evidence of CAD in diabetic patients without known CAD and the impact of symptoms and scintigraphic findings on prognosis [26]. Objective evidence of CAD was found in $39 \%$ of 826 asymptomatic diabetic patients, in $51 \%$ of 151 diabetic patients with shortness of breath (SOB), and in $44 \%$ of 760 diabetic patients with angina. Overall, patients with a normal MPS had quite a good prognosis irrespective of symptomatic status, even though it was not $<1 \%$. Patients with an abnormal MPS had a significantly worse outcome. Of note, there was no prognostic difference in patients with abnormal MPS when asymptomatic patients and patients with angina were compared (Figures 2 and 3 ). By contrast, patients with SOB had a very high event rate, reflecting in part that these patients had more often suffered a silent myocardial infarction than asymptomatic patients and patients with angina. In the multivariate Cox proportional hazards model, age, hypertension, SOB, extent of scarring, and extent of ischemia were independent predictors of events. Hypercholesterolemia and family history of CAD tended to be independent predictors of events. Of note, angina was not a significant predictor of critical events in this model, but SOB was. MPS added incremental information to clinical and prescan information to predict outcome, indicating that MPS seems to be valuable for risk stratification of asymptomatic diabetic patients with respect to the diagnosis of CAD and its prognosis.

An even more difficult question is the "warranty period" of a normal MPS regarding prognosis. There is data suggesting that it is only around 1 year in diabetic patients [30].

Calcium scoring and coronary angiography by computed tomography has emerged as a screening tool for CAD. Schurgin et al. evaluated 139 diabetic patients with respect to the calcium score as assessed by computed tomography [31]. Diabetic patients were then compared to a randomly selected nondiabetic patient group. Patients with diabetes had a significantly higher prevalence of calcium scores $>400$ $(25.9 \%)$ compared with the randomly selected $(7.2 \%)$ and matched $(14.4 \%)$ nondiabetic control group. Scores above the range of 400 have been reported to be highly predictive of abnormal MPS and subsequent coronary events. Raggi et al. evaluated the prognostic value of calcium score measurements in diabetic patients [32]. Mortality from all causes was increased in asymptomatic patients with diabetes in proportion to the screening calcium score. Nonetheless, subjects without coronary artery calcium had a low short-term risk of death even in the presence of diabetes mellitus. Moreover, the presence of any degree of coronary ar-

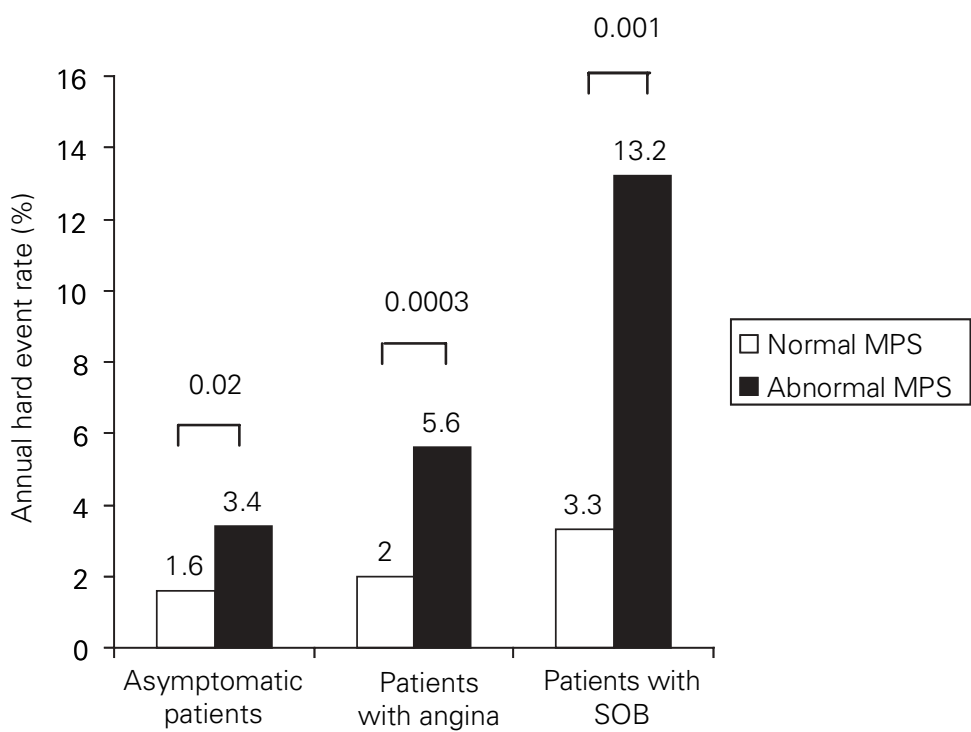

Figure 2. Annual hard event rates (cardiac death or nonfatal myocardial infarction) as a function of symptoms and MPS (myocardial perfusion SPECT) findings ( $n=$ 1,430; adapted from [26]). SOB: shortness of breath

Abbildung 2. Jährliche Ereignisraten (kardialer Tod oder nichtfataler Myokardinfarkt) als Funktion der Symptomatik und der MPS-Resultate ( $n=1430$; modifiziert nach [26]). SOB: Dyspnoe.

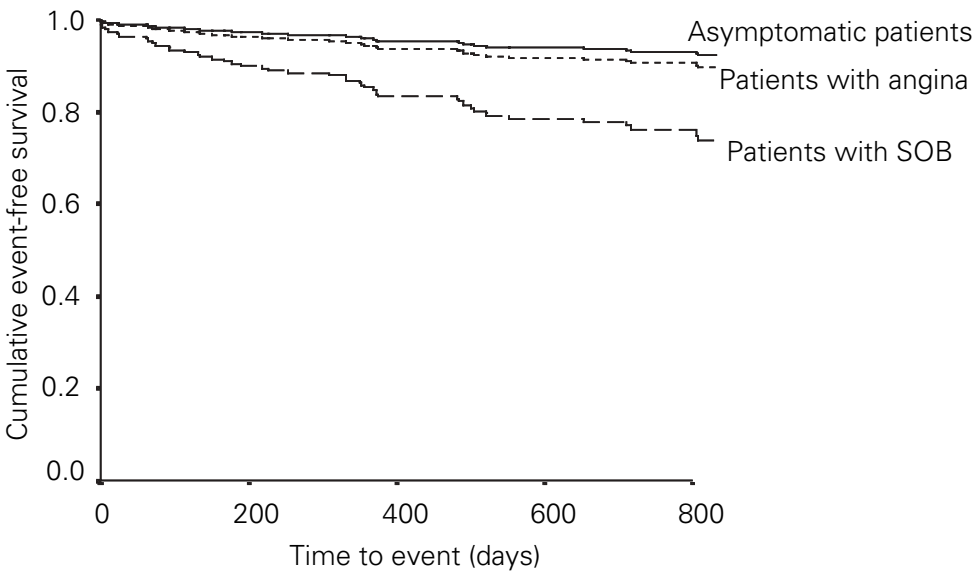

Figure 3. Kaplan-Meier survival curves in patients with abnormal MPS $(n=509$; adapted from [26]). SOB: shortness of breath.

Abbildung 3. Kaplan-Meier-Überlebenskurven bei Patienten mit abnormem MPS ( $n$ = 509; modifiziert nach [26]). SOB: Dyspnoe.

tery calcium in patients with diabetes mellitus portended a higher risk for all-cause mortality than in nondiabetic patients.

Patients with autonomic cardiac neuropathy have a higher incidence of silent myocardial ischemia than patients without autonomic cardiac neuropathy [19, $33,34]$. Furthermore, the former have a significantly higher mortality rate than the latter, $30 \%$ and $13 \%$, 
respectively [19, 33, 34]. It seems that evaluation of cardiac autonomic neuropathy might help to identify diabetic patients at particularly high risk.

\section{Clinical Implications}

The epidemic of diabetes has left us with the challenge of identifying those asymptomatic individuals with diabetes who have silent or occult CAD. Data is supporting the fact that not symptoms play the important role for patient prognosis but objective evidence of CAD. It is also crucial to bear in mind that diabetic patients can present with atypical symptoms of CAD (e.g., with symptoms of easy fatigability, exertional SOB, or indigestion).

An individual assessment of cardiac risk is important to decide if a diabetic patient should be tested and also when the patient should be reevaluated (warranty period of a normal test) which has plenty of implications (e.g., patient safety, radiation exposure, costs). Generally, it appears that clinical information adds incremental prognostic value over perfusion results and can further risk-stratify MPS results. These factors include patient gender, age, presence of peripheral vascular disease, microalbuminuria, retinopathy, autonomic neuropathy, or abnormal resting ECG. The consensus paper of the American Diabetes Association provides useful information regarding diagnostic strategies in diabetic patients [35]. Even though, these recommendations were based on the clinical judgment of a panel of experts rather than on published data [36].

The question of therapeutic approaches in silent CAD is an important question of ongoing debate. The data dealing with this issue is scarce. There is only one pilot study in a general population that has prospectively addressed different therapeutic approaches in silent CAD: the Asymptomatic Cardiac Ischemia Pilot (ACIP) study [37]. The study demonstrated that a strategy of initial revascularization appeared to improve the prognosis of a general population with silent CAD compared with angina-guided medical therapy [37]. In addition, recent data from the Mayo Clinic provide some evidence regarding the value of MPS in relation to outcome in diabetic patients [38]. They evaluated 826 asymptomatic diabetic patients without prior CAD and abnormal MPS. Revascularization was performed in $21 \%$ of patients with high-risk MPS. Revascularization revealed to be an independent predictor of improved survival in these patients.

It might also be that rigorous primary and secondary prevention by statins will lead to stabilization and regression of CAD in diabetic patients. There are several studies demonstrating that there was a significant decrease of coronary calcium scores in patients effectively treated by statins [38, 39]. 


\section{References}

1. Zimmet P, Alberti KG, Shaw J. Global and societal implications of the diabetes epidemic. Nature 2001;414:782-7.

2. Haffner SM, Lehto S, Ronnemaa T, et al. Mortality from coronary heart disease in subjects with type 2 diabetes and in nondiabetic subjects with and without prior myocardial infarction. N Engl J Med 1998;339:229-34.

3. Goraya TY, Leibson CL, Palumbo PJ, et al. Coronary atherosclerosis in diabetes mellitus: a population-based autopsy study. J Am Coll Cardiol 2002;40:946-53.

4. Kannel WB, McGee DL. Diabetes and cardiovascular disease. The Framingham study. JAMA 1979;241:2035-8.

5. Grundy SM, Benjamin IJ, Burke GL, et al. Diabetes and cardiovascular disease: a statement for healthcare professionals from the American Heart Association. Circulation 1999; 100:1134-46.

6. Kannel WB, McGee DL. Diabetes and cardiovascular risk factors: the Framingham study. Circulation 1979;59:8-13.

7. Langer A, Freeman MR, Josse RG, et al. Metaiodobenzylguanidine imaging in diabetes mellitus: assessment of cardiac sympathetic denervation and its relation to autonomic dysfunction and silent myocardial ischemia. J Am Coll Cardiol 1995;25:610-8.

8. Ambepityia G, Kopelman PG, Ingram D, et al. Exertional myocardial ischemia in diabetes: a quantitative analysis of anginal perceptual threshold and the influence of autonomic function. J Am Coll Cardiol 1990;15:72-7.

9. Hikita $\mathrm{H}$, Kurita A, Takase B, et al. Usefulness of plasma beta-endorphin level, pain threshold and autonomic function in assessing silent myocardial ischemia in patients with and without diabetes mellitus. Am J Cardiol 1993;72: 140-3.

10. Rosen SD, Paulesu E, Nihoyannopoulos P, et al. Silent ischemia as a central problem: regional brain activation compared in silent and painful myocardial ischemia. Ann Intern Med 1996;124:939-49.

11. Zellweger MJ, Pfisterer ME. Silent coronary artery disease in patients with diabetes mellitus. Swiss Med Wkly 2001;131: 427-32.

12. Langer A, Freeman MR, Josse RG, et al. Detection of silent myocardial ischemia in diabetes mellitus. Am J Cardiol 1991;67:1073-8.

13. Koistinen MJ. Prevalence of asymptomatic myocardial ischaemia in diabetic subjects. BMJ 1990;301:92-5.

14. Fleg JL. Prevalence and prognostic significance of exercise-induced silent myocardial ischemia in apparently healthy subjects. Am J Cardiol 1992;69:14B-8B.

15. MiSAD. Prevalence of unrecognized silent myocardial ischemia and its association with atherosclerotic risk factors in noninsulin-dependent diabetes mellitus. Milan Study on Atherosclerosis and Diabetes (MiSAD) Group. Am J Cardiol 1997;79:134-9.

16. Wackers FJ, Young LH, Inzucchi SE, et al. Detection of silent myocardial Ischemia in Asymptomatic Diabetic subjects: The DIAD study. Diabetes Care 2004;27:1954-61.

17. Nesto RW, Watson FS, Kowalchuk GJ, et al. Silent myocardial ischemia and infarction in diabetics with peripheral vascular disease: assessment by dipyridamole thallium-201 scintigraphy. Am Heart J 1990;120:1073-7.

18. Rutter MK, McComb JM, Brady S, et al. Silent myocardial ischemia and microalbuminuria in asymptomatic subjects with non-insulin-dependent diabetes mellitus. Am J Cardiol 1999;83:27-31.

19. Vinik Al, Maser RE, Mitchell BD, et al. Diabetic autonomic neuropathy. Diabetes Care 2003;26:1553-79.

20. Kannel WB, McGee DL. Diabetes and glucose tolerance as risk factors for cardiovascular disease: the Framingham study. Diabetes Care 1979;2:120-6.
21. Donnan PT, Boyle DI, Broomhall J, et al. Prognosis following first acute myocardial infarction in type 2 diabetes: a comparative population study. Diabet Med 2002;19:448-55.

22. Weiner DA, Ryan TJ, Parsons L, et al. Significance of silent myocardial ischemia during exercise testing in patients with diabetes mellitus: a report from the Coronary Artery Surgery Study (CASS) Registry. Am J Cardiol 1991;68:729-34.

23. Pancholy SB, Schalet B, Kuhlmeier V, et al. Prognostic significance of silent ischemia. J Nucl Cardiol 1994;1:434-40.

24. Rajagopalan N, Miller TD, Hodge DO, et al. Identifying high-risk asymptomatic diabetic patients who are candidates for screening stress single-photon emission computed tomography imaging. J Am Coll Cardiol 2005;45:43-9.

25. Rajagopalan N, Miller TD, Hodge DO, et al. Identifying high risk asymptomatic diabetics who are candidates for screening stress SPECT. J Am Coll Cardiol 2002;39:382A.

26. Zellweger MJ, Hachamovitch R, Kang X, et al. Prognostic relevance of symptoms versus objective evidence of coronary artery disease in diabetic patients. Eur Heart J 2004;25:543-50.

27. Giri S, Shaw LJ, Murthy DR, et al. Impact of diabetes on the risk stratification using stress single-photon emission computed tomography myocardial perfusion imaging in patients with symptoms suggestive of coronary artery disease. Circulation 2002;105:32-40.

28. Kang $\mathrm{X}$, Berman DS, Lewin $\mathrm{H}$, et al. Comparative ability of myocardial perfusion single-photon emission computed tomography to detect coronary artery disease in patients with and without diabetes mellitus. Am Heart J 1999; 137:949-57.

29. Kang X, Berman DS, Lewin HC, et al. Incremental prognostic value of myocardial perfusion single photon emission computed tomography in patients with diabetes mellitus. Am Heart J 1999;138:1025-32.

30. Hachamovitch R, Hayes S, Friedman JD, et al. Determinants of risk and its temporal variation in patients with normal stress myocardial perfusion scans: what is the warranty period of a normal scan? J Am Coll Cardiol 2003;41:1329-40.

31. Schurgin S, Rich S, Mazzone T. Increased prevalence of significant coronary artery calcification in patients with diabetes. Diabetes Care 2001;24:335-8.

32. Raggi P, Shaw LJ, Berman DS, et al. Prognostic value of coronary artery calcium screening in subjects with and without diabetes. J Am Coll Cardiol 2004;43:1663-9.

33. Vinik Al, Mehrabyan A. Diagnosis and management of diabetic autonomic neuropathy. Compr Ther 2003;29:130-45.

34. Maser RE, Mitchell BD, Vinik Al, et al. The association between cardiovascular autonomic neuropathy and mortality in individuals with diabetes: a meta-analysis. Diabetes Care 2003;26:1895-901.

35. ADA. Consensus development conference on the diagnosis of coronary heart disease in people with diabetes: 10-11 February 1998, Miami, Florida. American Diabetes Association. Diabetes Care 1998;21:1551-9.

36. Wackers FJ, Zaret BL. Detection of myocardial ischemia in patients with diabetes mellitus. Circulation 2002;105:5-7.

37. Davies RF, Goldberg AD, Forman S, et al. Asymptomatic Cardiac Ischemia Pilot (ACIP) study two-year follow-up: outcomes of patients randomized to initial strategies of medical therapy versus revascularization. Circulation 1997;95 2037-43.

38. Sorajja P, Chareonthaitawee P, Rajagopalan N, et al. Improved survival in asymptomatic diabetic patients with high-risk SPECT imaging treated with coronary artery bypass grafting. Circulation 2005;112:1311-6.

39. Callister TQ, Raggi P, Cooil B, et al. Effect of HMG-CoA reductase inhibitors on coronary artery disease as assessed by electron-beam computed tomography. N Engl J Med 1998; 339:1972-8.

\section{Address for Correspondence PD Dr. Michael J.} Zellweger Kardiologische Klinik Universitätsspital

Petersgraben 4 4031 Basel Switzerland Phone $(+41 / 61)$

265-5473,

Fax -4598

e-mail:mzellweger@ uhbs.ch 